\title{
EVALUATION THE EFFECT OF ERBIUM CHROMIUM LASER SYSTEM FOR CAVITY PREPARATION ON MARGINAL INTEGRITY OF RESIN COMPOSITE
}

\author{
Mostafa Mohamed Maghraby*, Ali Saafan ${ }^{* *}$, Haythem Moharrum*** and Moanes Soliman****
}

\begin{abstract}
The aim of this study to evaluate the effect of Er,Cr:YSGG laser versus conventional bur on marginal integrity of resin composite for cavity preparation. 40 extracted human permanent molars were used in this study and were divided into two main equal groups according to cavity preparation technique (class V cavities prepared by conventional diamond bur and Er,Cr:YSGG laser). Each group was divided into two subgroups according to subjection to load cycling. Each subgroup was further sub divided into two classes according to aging period ( 7 days and 3 months). Scotch bond universal adhesive system was applied to all cavities according to the manufacturers instruction and cured for 20 seconds, then restored with composite resin filtek Z350 and light cured for 40 seconds. 2000 cycles were applied at loads between a minimum $10 \mathrm{~N}$ and a maximum $89 \mathrm{~N}$ force with a load profile in the form of a sine wave at frequency of $1 \mathrm{HZ}$.Samples were aged in distilled water according to the subdivision ( 7 days \& 3 months). Data were analyzed with Kruskal-Wallis and Mann-Whitney U tests after methylene blue dye immersion for 24 hours and mesiodistal sectioning through the center of the restoration. Results of this study will be summarized in statistically nonsignificant difference between conventional and laser cavity groups in the microleakage scores.
\end{abstract}

KEYWORDS : Er,Cr:YSGG Laser,Class V, Marginal Integrity, Load Cycling, Dye Penetration, Microleakage.

\section{INTRODUCTION}

In recent years the introduction of adhesive systems has greatly altered cavity preparation techniques and as aresult conservative cavity preparation techniques have gained popularity. These systems minimize the requirement for retention and resistance form for cavity preparation. Conventional cavity preparation techniques utilizing a handpiece with a carbide or diamond bur have been used for many years. However tooth preparation may be unpleasant experience for patients due to the bone

\footnotetext{
* Researcher in National Institute of Lasers, National Institute of Laser Sciences, Laser Dentistry, Cairo, Egypt.

** Professor of Laser Dentistry in Institute, Cairo University, National Institute of Laser Sciences, Laser Dentistry, Cairo, Egypt.

*** Lecturer, National Institute of Laser Sciences, Laser Dentistry Cairo, Egypt.

**** Lecturer, Misr University For Science and Technology, Operative Dentistry, Cairo, Egypt.
} 
conducted noise and vibration. ${ }^{(1)}$.Additionally conventional cavity preparation usually requires local anesthesia and can involve excessive loss of tooth tissue $^{(2,3)}$.In minimally invasive dentistry, the main goal is to preserve as much sound enamel and dentin as possible during cavity preparation, and this concept has lead the dental profession to search for more innovative preparation techniques such as lasers especially erbium family ${ }^{(4-5)}$.

Laser application in cavity preparation has had widespread acceptance.Erbium family lasers can cut enamel and dentin efficiently due to their significant water and hydroxyapatite absorption.

Histological studies of pulpal tissues of teeth irradiated by Er,Cr:YSGG laser show minimal inflammatory reactions ${ }^{(6-7)}$. It has been indicated that application of Er,Cr:YSGG laser beam to enamel and dentin surfaces can cause a number of microscopic changes including cration of minute surface irregularities, lack of smear layer formation, and creation of minimal cracks ${ }^{\left({ }^{8}\right)}$. Microirregularities created by application of pulsed erbium lasers will favor conditioning of the hard dental tissues more specifically on enamel, in which a rough microtexture is left behind due to the involved micromechanical ablation process ${ }^{(9)}$.

The smear layer is an adherent layer of debris produced by the cutting of the enamel and dentin..$^{(10)}$

Although the smear layer acts as a "diffusion barrier" that reduces the permeability of dentin, it is also considered an obstacle that must be removed to permit application of adhesive to the underlying dentin.

Laser preparation techniques have been shown to produce differences in the surface morphology and the smear layer compared to a conventional bur-prepared surfaces ${ }^{(11-12)}$. The difference in smear layer characteristics may have an influence on adhesive bond strength ${ }^{(13)}$. It has been shown that different adhesive systems produce different effects on the smear layer ${ }^{(14-15)}$. Therefore it might be expected that the differences in surface alterations following the use of different cavity preparation techniques would influence microleakage with different adhesive systems.

\section{MATERIALS AND METHODS}

- Er,Cr: YSGG laser, (Waterlase MD Laser, BioLase - G6 tips 600 micron ).

- Conventional handpiece (W\&H hand piece ).

- Load cycling machine (Model 3345; Instron Instruments Ltd., USA).

- Digital microscope (Scope Capture Digital Microscope, China) (X40).

- A light cure resin composite Filtek Z/350.

- A light cure self-etching adhesive system Scotch Bond Universal Adhesive system.

- Methylene blue dye 2\% was prepared in the laboratory of faculty of pharmacy, Alexandria University.

\section{- Acrylic resin.}

\section{Procedure}

A total number of 40 extracted caries-free human permanent molars were used in this study.

The forty teeth were randomly divided into two main equal groups, 20 teeth each; according to the cavity preparation procedures. Group I (GpI), represented class $\mathrm{v}$ cavities prepared by conventional bur technique, while group II (Gp II), represented class $\mathrm{v}$ cavities prepared by Er,Cr:YSGG laser Biolase system. Each group was divided into two subgroups, 10 teeth each, according to subjection to load cycling ((L) either (L1) not subjected to load cycling, while the other subgroup (L2) subjected to load cycling. Each subgroup was further subdivided into two classes, five teeth each according to the aging period (A), in (A1) the teeth were aged for 7 days; whereas the in (A2) the teeth were aged for 3 months. 
Standardized class V cavities (3 $\mathrm{mm}$ wide, $2 \mathrm{~mm}$ high and $1.5 \mathrm{~mm}$ deep) were prepared on the buccal and lingual surfaces of the teeth. In group I (GpI) 40 cavities on the buccal and lingual surfaces of teeth; 20 cavities each surface, were prepared by conventional bur technique using diamond bur (W\&H hand piece). While In group II (Gp II) 40 cavities on the buccal and lingual surfaces of teeth; 20 cavities each surface, were prepared by erbium chromium yttrium scandium gallium garnet Er:CrYSGG laser ((Waterlase MD Laser, BioLase - G6 tips 600 micron) emitting photons at a wavelength of $2.940 \mathrm{~nm}$. At the beginning of cavity preparation, we carefully performed laser irradiation in a contact mode to remove enamel with a focused beam of $6 \mathrm{~W}$ at 50\% air pressure level and $30 \%$ water level and $20 \mathrm{HZ}$ frequency. As enamel removal progressed and the treated cavity floor became deeper and closer to the underlying dentin layer, the power was reduced to $4 \mathrm{~W}$ at $50 \%$ air level, $30 \%$ water level, frequency $50 \mathrm{HZ}$ and cavities were carefully finished by means of the non-contact irradiation mode. (see figure 1).

Scotch Bond Universal Adhesive system was applied to all cavities according to the manufacturers' instructions then cured for 20 seconds with halogen curing unit (Hilux, Benlioglu, Turkey). All cavities in group $\mathrm{C} 1$ and $\mathrm{C} 2$ were restored with composite resin Filtek Z350, then light cured for $40 \mathrm{sec}-$ onds with Halogen curing unit. All cavities in both groups $\mathrm{C} 1, \mathrm{C} 2$ were finished and polished with flexible discs of different grits by low speed hand-piece (NSK, low speed). All specimens were then stored in distilled water at room temperature for 24 hours.

Samples of subgroup (L1) were not subjected to load cycling while samples of subgroup (L2) were subjected to load cycling. Each sample in (L2) underwent 2000* cycles at loads between a minimum $10 \mathrm{~N}$ and a maximum $89 \mathrm{~N}$ force with a load profile in the form of a sine wave at frequency of $1 \mathrm{~Hz}$.

The samples were aged in distilled water, in class $\left(A_{1}\right)$ the samples were aged for 7 days, while

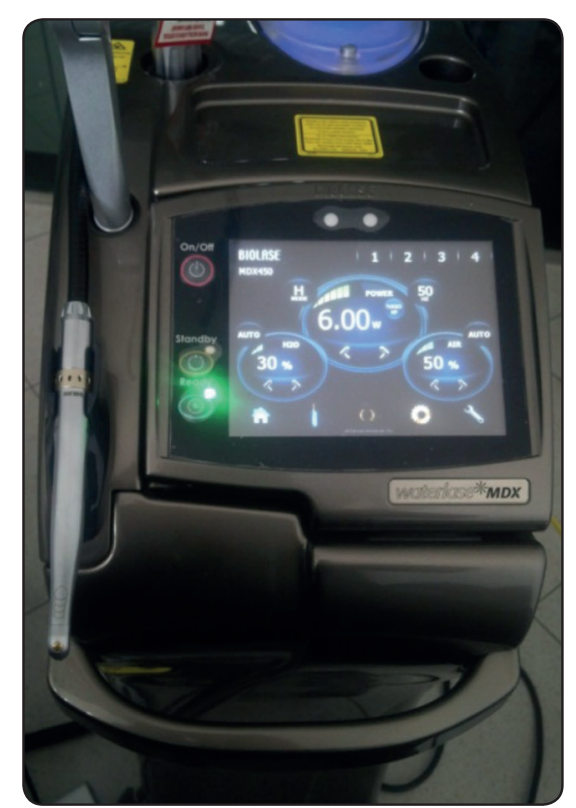

Fig. (1) Show parameters of cavity preparation by Er:Cr-YSGG laser.

in class $\left(A_{2}\right)$ they were aged for 3 months. The distilled water was changed every week.

The crown and root structure were covered with 2 coats of nail varnish leaving a $1 \mathrm{~mm}$ window around cavity margins. The samples were then immersed in $2 \%$ methylene blue solution for 24 hours. Teeth were then removed from the dye, washed under running water for 10 minutes to remove excess dye then left to dry. Each tooth was sectioned vertically mesio-distally through the center of the restoration into two halves using a diamond disc at low speed under coolant. The two split sections were cleaned carefully with alcohol to remove cutting debris. After rinsing, dye penetration was assessed under a USB digital microscope (Scope Capture Digital Microscope, China) (X40). Dye penetration was scored for both enamel and dentin margins on a scale from 0 to 3 :

$0=$ no microleakage.

$1=$ dye penetration within $1 / 3$ of cavity wall.

$2=$ dye penetration within $2 / 3$ of cavity wall.

$3=$ dye penetration spreading along the axial wall. 


\section{RESULTS}

- Data analysis was performed in several steps. Initially, frequent distribution of leakage scores (\%) for all groups was compared by KurskalWallis test followed by Mann-whitney test to evaluate the significance between subgroups for microleakage results. Results of this study will be summarized in the following points :

- The difference between conventional and laser cavity groups in the microleakage scores mean values that shows a statistically non-significant difference were microleakage of conventional cavity preparation has a mean (1.150631) while microleakage of laser cavity preparation has

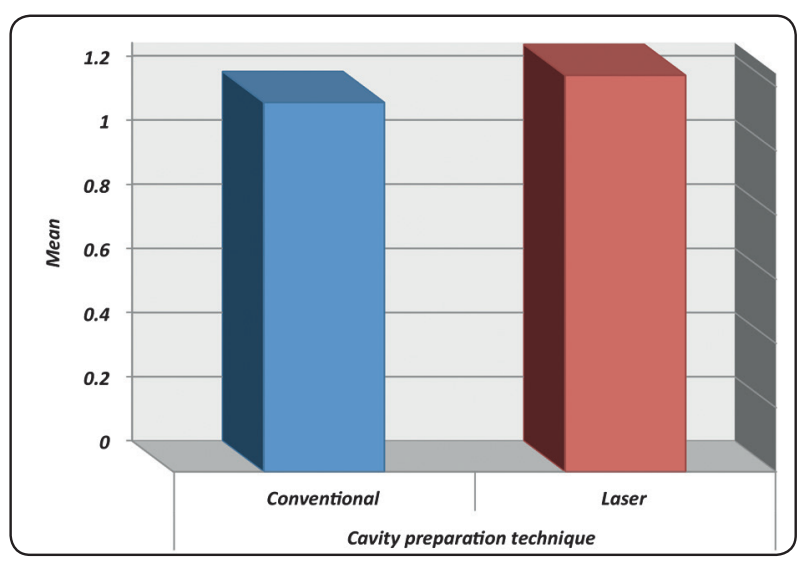

Fig. (2) Column chart of leakage scores mean value as function of cavity preparation technique.

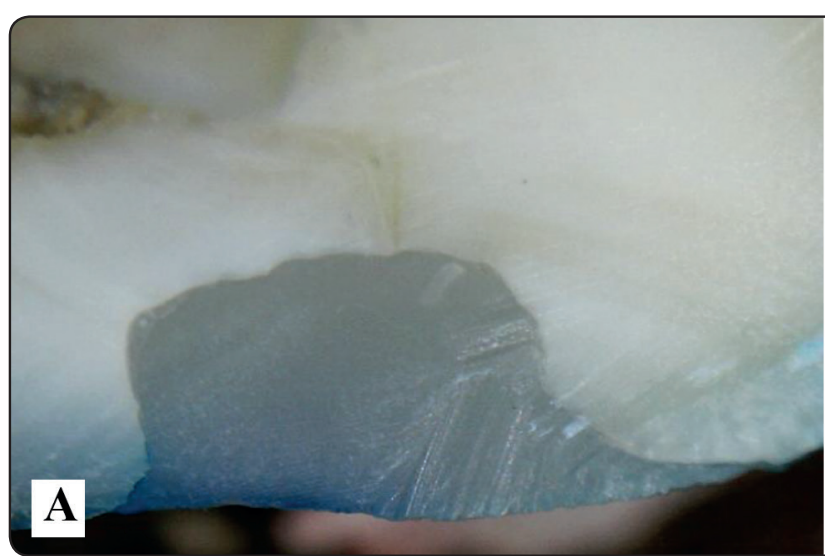

B a mean of (1.23505). the $\mathrm{p}$ value is 0.367 which is non significant.. (see- figure 2-3 ).

- Data analysis was performed using KurskalWallis test followed by Mann-whitney test to evaluate the significance between subgroups of seven days and three months for microleakage results.

- The difference between seven days and three months subgroups in the microleakage scores mean values that shows a statistically significant difference were microleakage of seven days aging has a mean (0.905492) while microleakage of three months aging has a mean of (1.480189). the $\mathrm{p}$ value is $<0.0001$ which is significant. (see- Figure 4-5-6 )

- Data analysis was performed using KurskalWallis test followed by Mann-whitney test to evaluate the significance between subgroups of non loaded and loaded for microleakage results.

- The difference between non loaded and loaded subgroups in the microleakage scores mean values that shows a statistically significant difference were microleakage of cavities without load cycling has a mean (1.047159) while microleakage of cavities with load cycling has a mean of (1.338523). The p value is 0.0014 which is significant. -.(see - Figure 7-8-9)

Fig. (3) Show dye penetration of (A) conventional technique, without load cycling and aged for 7days and (B) laser technique, without load and aged for 7 days. Photo A record score 2 (dye penetration within 2/3 of cavity wall). Photo B record score 1 (dye penetration within $1 / 3$ of cavity wall). 
- Data analysis was performed using KurskalWallis test followed by Mann-whitney test to evaluate the significance between subgroups of occlusal and gingival margin for microleakage results.

- The difference between occlusal and gingival margins in the microleakage scores mean values that shows a statistically non significant difference were microleakage of occlusal margin has a mean (1.106845) while microleakage of gingival margin has a mean of (1.278836). The $\mathrm{p}$ value is 0.0641 which is non significant (see figure 10)

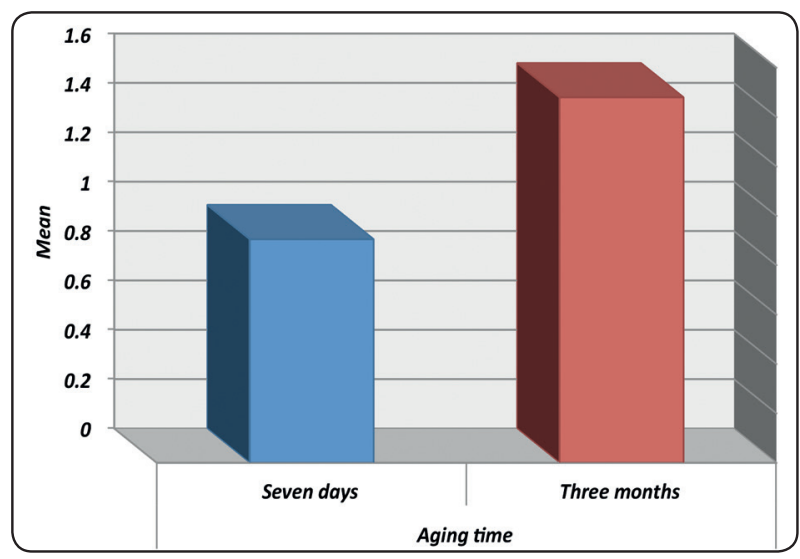

Fig. (4) Column chart of leakage scores mean value as function of aging time.

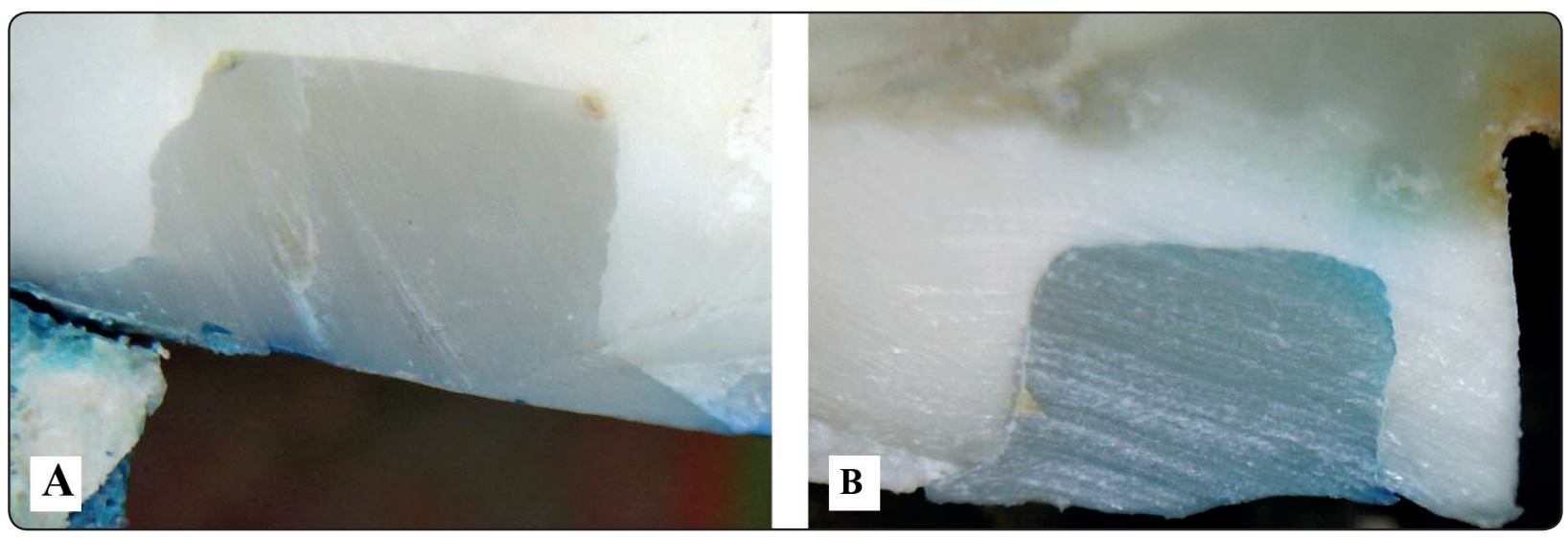

Fig. (5) Show dye penetration of (A) conventional technique with loaded and aged for 7days and (B) conventional technique, without load and aged for 3 months. Photo A record score 1(dye penetration within 1/3 of cavity wall) Photo B record score 3 (dye penetration spreading along the axial wall.)

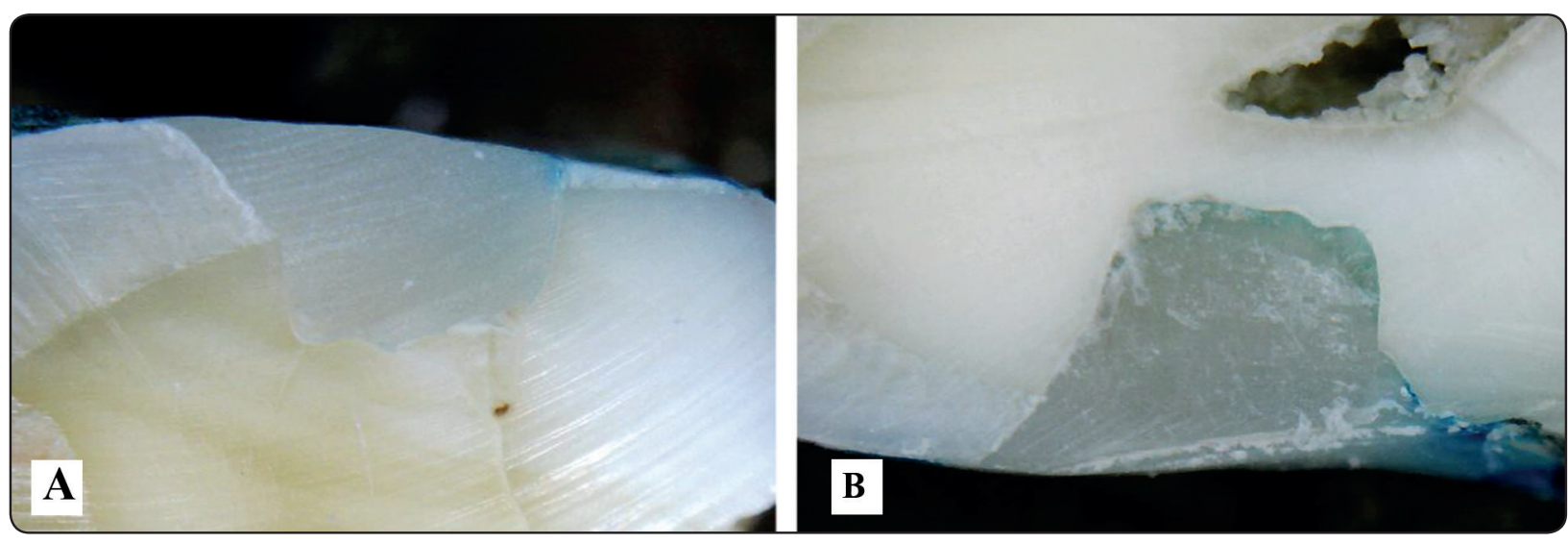

Fig. (6) Show dye penetration of (A) laser preparation technique, without load and aged for 7days and (B) laser preparation technique, without load and aged for 3 months. Photo A record score 1(dye penetration within 1/3 of cavity wall). Photo B record score 3 (dye penetration spreading along the axial wall.). 
Figure (10) Column chart of leakage scores mean value as function of cavity margin

- The highest leakage score in group of laser cavity preparation was three months gingivally group and the least was seven days occlusally group. (Table 1 - figure 11).

- The highest leakage score in group of conventional cavity preparation was three months gingivally group and the least was seven days occlusally group. ( Table 1 - figure 11 ).

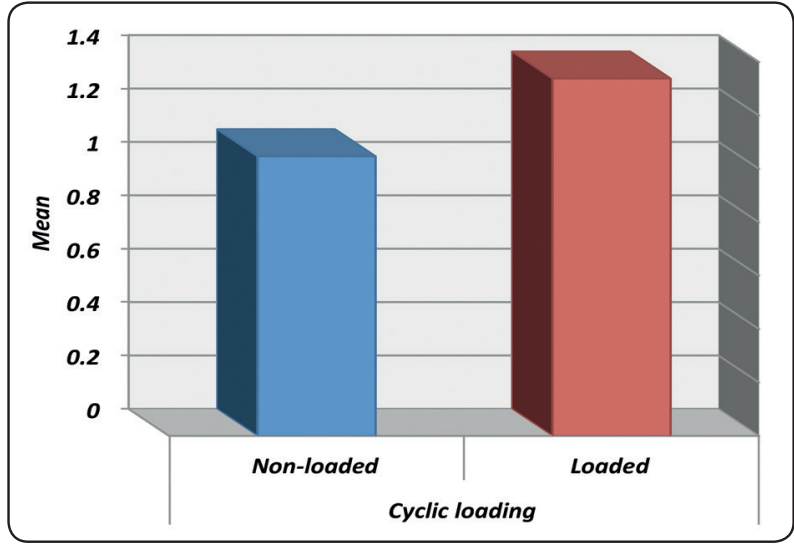

Fig. (7) Column chart of leakage scores mean value as function of cyclic loading.

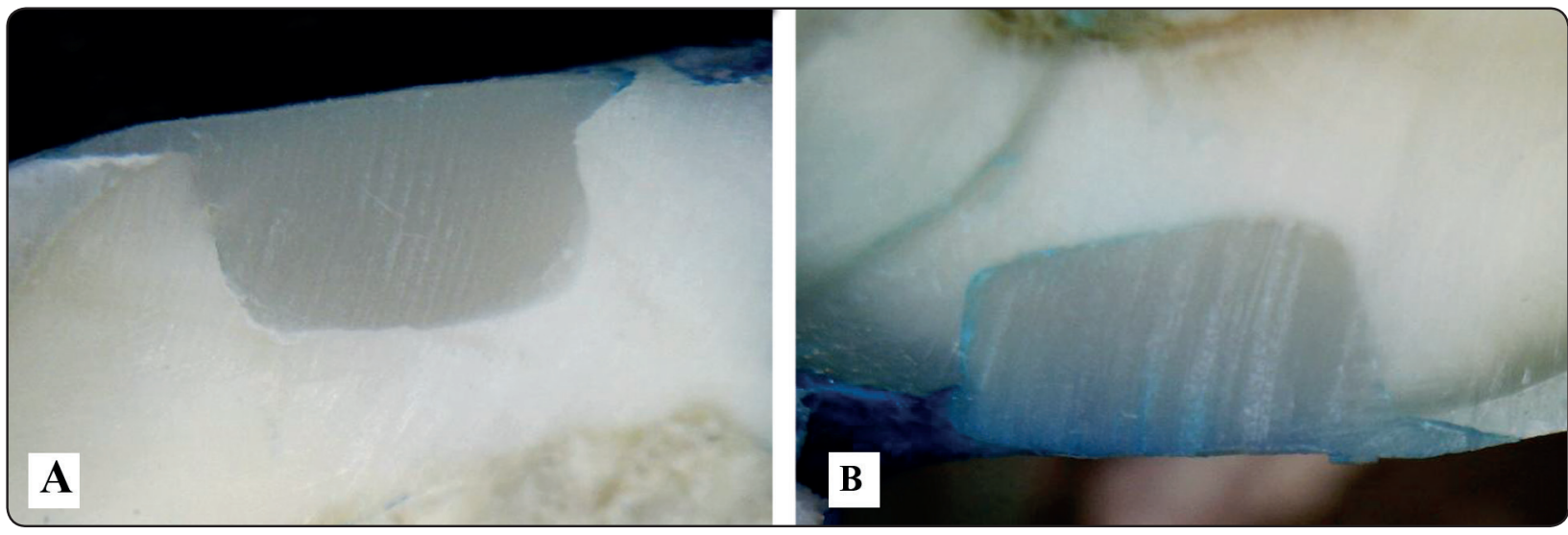

Fig. (8) Show dye penetration of (A) Conventional technique, without load and aged for 3 months and (B) Conventional technique with load cycling and aged for 3 months. Photo A record score 1(dye penetration within 1/3 of cavity wall ). Photo B record score 3 (dye penetration spreading along the axial wall.).

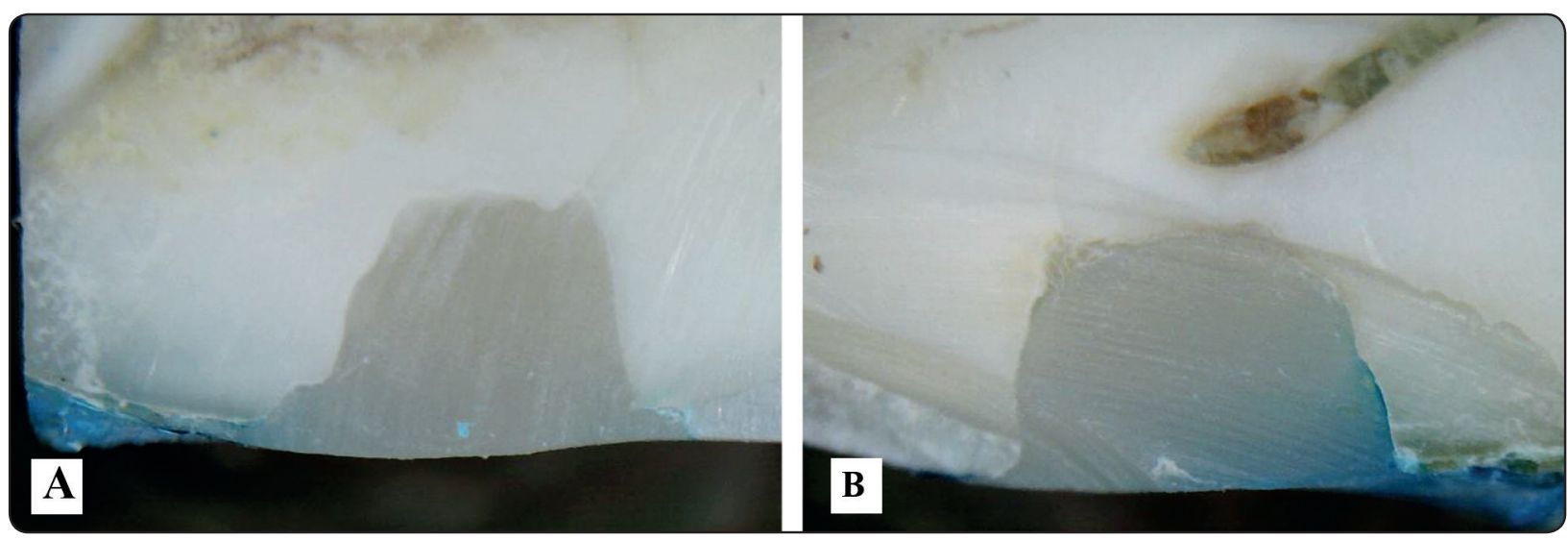

Fig. (9) Show dye penetration of (A) laser preparation technique, without load and aged for 3 months and (B) laser preparation technique with loaded and aged for 3 months . Photo A record score 1 (dye penetration within $1 / 3$ of cavity wall ). Photo B record score 2 (dye penetration within $2 / 3$ of cavity wall). 


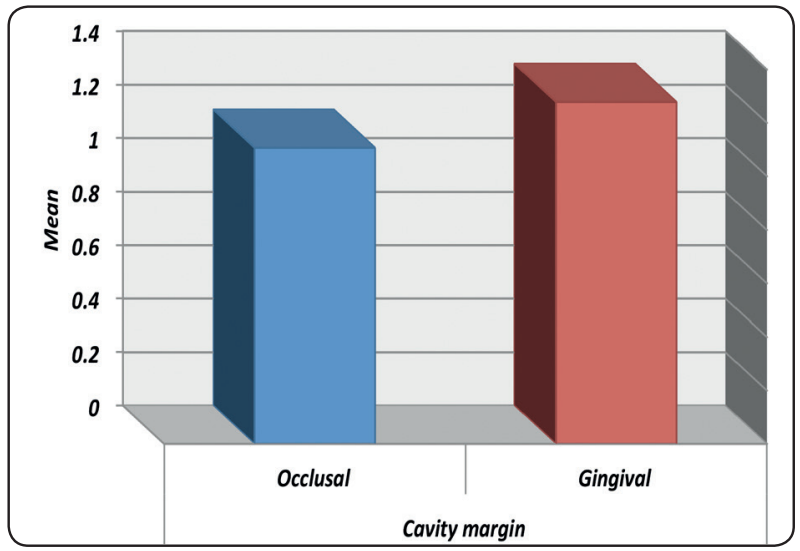

Fig. (7) Column chart of leakage scores mean value as function of cyclic loading.

TABLE (1) Leakage scores results $(M e a n \pm S D)$ for both cavity groups as function of aging, margin and cyclic loading

\begin{tabular}{|c|c|c|c|c|c|c|c|c|c|}
\hline \multicolumn{2}{|c|}{ Variables } & \multicolumn{4}{|c|}{ Seven days } & \multicolumn{4}{|c|}{ Three months } \\
\hline & & \multicolumn{2}{|c|}{ Non-loaded } & \multicolumn{2}{|c|}{ Loaded } & \multicolumn{2}{|c|}{ Non-loaded } & \multicolumn{2}{|c|}{ Loaded } \\
\hline & & Mean & $\pm \mathrm{SD}$ & Mean & $\pm \mathrm{SD}$ & Mean & $\pm \mathrm{SD}$ & Mean & $\pm \mathrm{SD}$ \\
\hline \multirow{2}{*}{$\begin{array}{c}\text { Conventional } \\
\text { cavity }\end{array}$} & Occlusal & 0.7 & 0.128 & 1 & 0.262 & 1 & 0.268 & 1.5 & 0.189 \\
\hline & Gingival & 0.727 & 0.117 & 1 & 0.136 & 1.5 & 0.151 & 1.778 & 0.158 \\
\hline \multirow[t]{2}{*}{ Laser cavity } & Occlusal & 0.75 & 0.098 & 1 & 0.262 & 1.333 & 0.253 & 1.571 & 0.289 \\
\hline & Gingival & 0.9 & 0.108 & 1.167 & 0.178 & 1.467 & 0.142 & 1.692 & 0.185 \\
\hline
\end{tabular}

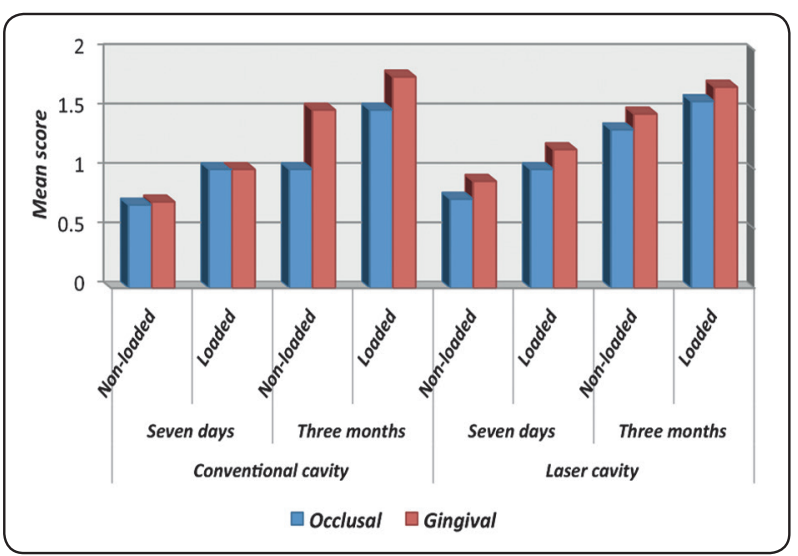

Fig. (11) Histogram of leakage scores mean value for both cavity groups as function of aging, margin and cyclic loading

\section{DISCUSSION}

The introduction of the Er:Cr:YAG laser for cavity preparation could results in a surface with significantly different morphologies to that obtained by conventional methods and these morphologies have a great effect on microleakage.

The overall leakage score values in the present study revealed that there was statistically non-significant difference between conventional and laser cavity preparation techniques and this confirmed the previous studies that Er:Cr:YAG laser to be as effective as the conventional method for preparing adhesive preparations.

Hossain et al, 2002 and silvana jukic et al 2009 investigated the effect of laser and diamond bur to 
microleakage of Class V cavities on human teeth. They reported no statistically significant differences between the tested groups. These studies attributed their results to the absence of a smear layer, dentinal tubule openings and exposed enamel rods are generally observed in SEM evaluation and these micromorphological characteristics create areas of retention for adhesive bonding. ${ }^{(16-17)}$

However, there are controversial results regarding the microleakage with laser preparations. Some of them have demonstrated that lasers have a negative influence on marginal sealing (Emre ozel et al, 2009). Emre ozel found that, the probable explanation for this result is that the cavosurface margins produced by Er:YAG laser irradiation are quite rough in comparison with the margins produced by bur cutting. Therefore, this marginal contouring could result in increased microspacing and greater leakage.Also,Emre report that preparation with handpiece diamond bur allows the formation of thicker hybrid layer than does preparation with erbium chromium laser. ${ }^{(18)}$

On the other hand, Tahereh Fattah et al, 2013 found that use of Er,Cr: YSGG laser in preparing class $\mathrm{V}$ cavities was more influential than conventional bur technique in reducing microleakage due to it was a conservative technique in preparing cavities which make rough irregular surface without smear layer. Also, this might be attributed to different testing methods and conditions, adhesive system used and the varying nature of dentin as a substrate as well as resin composite used. ${ }^{(19)}$

Regarding the storage period, the results of leakage scores in the present study revealed there was significant difference in leakage scores values at three months storage period compared to seven days storage period.

Water can infiltrate and decrease the mechanical properties of the polymer matrix by swelling and reducing the frictional forces between the polymer chains. This causes plasticization of the resin, which makes it weaker ${ }^{(20-21)}$.
On the other hand, Amaral FLB et al 2010, found that adhesion to Er:YAG laser-irradiated enamel was not affected by the methods used to simulate degradation of the adhesive interface. The explanation for this result may be described to the Er:YAG laser's micro-ablative process, which causes vaporization of water and dental organic components and subsequent micro-explosive destruction of inorganic substrates, resulting in a rough and irregular surface. This morphology of laser-prepared cavities leads to an increasing area of adhesive interface, which probably needs more time to be degraded. ${ }^{(22)}$

The results of this study showed that cyclic loading had significant effect on microleakage.

When load is applied on a flat surface perpendicular to the bonded interface, a compressive stress would be expected under the loading sphere in the middle of the tooth. Tensile strength would be expected to develop around the peripheries of bonded interface. It is commonly accepted that cyclic loading has a significant effect on leakage Osrio $\mathbf{R}$ etal, $2004{ }^{(23)}$. Moreover the enamel sealing of self-etching systems can be broken easily, and cyclic strains can be applied onto hybrid layers and adhesive layers, which can result in the acceleration of weakening of layers and increased microleakage. This was also in agreement with $\mathbf{E}$ Yassini et al,2012 who stated that the application of cyclic loading had a significant effect on the microleakage of adhesive restorations. ${ }^{(24)}$

On the other hand Samer Hakimeh et al, 2000 found that the use of the cyclic loading procedure did not have an increasing effect on the microleakage. These conflicting statements in the evaluation of the effects of load cycling procedures might be related to the variety of the tested materials and/ or the different cavity design and/or the different test methods and/or the properties of the hard tissues. ${ }^{(25)}$.

Regarding the location of cavity margin, the leakage of gingival located margin groups revealed 
that there was significant difference in leakage scores values compared to occlusal located groups. The increased leakage score at gingival margins might be due to bonding to dentin is much more technique and substrate-sensitive than bonding to enamel (Muhammed G ; Dayem R 2014). This is in agreement with Ozgul Baygin et al, 2012. ${ }^{(26-27)}$.

\section{CONCLUSIONS}

Within the limitations of this in vitro study, it may be concluded that;

1. The Er, Cr : YSGG laser was confirmed to be as effective as the conventional method for preparing adhesive preparations.

2. Modes of cavity preparation had no significant effect on microleakage

3. As the use of Er,Cr:YSGG laser is a new technology for restorative dentistry, it is suggested that further investiga- tion be conducted to establish a better understanding of bonding to lased surfaces.

\section{REFERENCES :}

1. Berggren U, Meynert G (1984) Dental fear and avoidance: causes, symptoms, and consequences. J Am Dent Assoc 109(2):247-251

2. Banerjee A, Kidd EA, Watson TF (2000) In vitro evaluation of five alternative methods of carious dentine excavation. Caries Res 34(2):144-150

3. Celiberti P, Francescut P, Lussi A (2006) Performance of four dentine excavation methods in deciduous teeth. Caries Res 40 (2):117-123

4. Murdoch-Kinch CA, McLean ME (2003) Minimally invasive dentistry. J Am Dent Assoc 134(4):87-94

5. Burnett LH Jr, Conceiçaõ EN, Pelinos JE, Eduardo CD (2001) Comparative study of influence on tensile bond strength of acomposite to dentin using Er:YAG laser, air abrasion, or air turbine for preparation of cavities. J Clin Laser Med Surg 19 (4):199-202

6. Eversole LR, Rizoiu I, Kimmel AI (1997) Pulpal response to cavity preparation by an erbium, chromium:YSGG laser-powered hydrokinetic system. J Am Dent Assoc 128(8):1099-1106

7. Rizoiu I, Kohanghadosh F, Kimmel AI, Eversole LR (1998) Pulpal thermal responses to an erbium, chromium: YSGG pulsed laser hydrokinetic system. Oral Surg Oral Med Oral Pathol Oral Radiol Endod 86(2):220-223

8. Hossain M, Nakamura Y, Yamada Y, Kimura Y, Matsumoto N, Matsumoto K (1999) Effects of Er,Cr:YSGG laser irradiation in human enamel and dentin: ablation and morphological studies. J Clin Laser Med Surg 17(4):155-159

9. Gutknecht N, Apel C, Schafer C, Lampert F (2001) Microleakage of composite fillings in Er,Cr:YSGG laser-prepared class II cavities. Lasers Surg Med 28(4):371-374

10. Van Meerbeek B, Van Landuyt K, de Munck J, Inoue S, Yoshida Y, Perdiao J, Lambrechts P, Peumans M (2006) Bonding to enamel and dentin. In: Summitt JB, Robbins JW, Hilton TJ, Schwartz RS (eds) Fundamentals of operative dentistry, 3rd edn. Quintessence, Chicago, p 188

11. Semeraro S, Mezzanzanica D, Spreafico D, Gagliani M, Re D,Tanaka T, Sidhu SK, Sano H (2006) Effect of different bur grinding on the bond strength of self-etching adhesives. Oper Dent 31(3):317-323

12. Lima LM, Motisuki C, dos Santos-Pinto L, dos SantosPinto A,Corat EJ (2006) Cutting characteristics of dental diamond burs made with CVD technology. Braz Oral Res 20(2):155-161

13. Van Meerbeek B, De Munck J, Mattar D, Van Landuyt K, Lambrechts P (2003) Microtensile bond strengths of an etch\&rinse and self-etch adhesive to enamel and dentin as a function of surface treatment. Oper Dent 28(5):647-660

14. Pangsrisomboon B, Harnirattisai C, Nilsri K, Burrow MF (2007) Microtensile bond strength of self-etching adhesive systems to differently prepared dentin. Am J Dent 20(4):259-262

15. Sattabanasuk V, Vachiramon V, Qian F, Armstrong SR (2007) Resin-dentin bond strength as related to different surface preparation methods. J Dent 35(6):467-575

16. M. Hossain, Y. Yamada, Y. Nakamura, Y. Murakami, Y. Tamaki, K. Matsumoto, "A study on surface roughness and microleakage test in cavities prepared by Er:YAG laser irradiation and etched bur cavities", Lasers in Medical Science, Volume 18, Issue 1, 2002.

17. Silvana Jukić Krmek \& Ivana Bogdan \& Paris Simeon \& Goranka Prpić Mehičić \& Davor Katanec \& Ivica Anić, 
"A three-dimensional evaluation of microleakage of class $\mathrm{V}$ cavities prepared by the very short pulse mode of the erbium:yttrium-aluminium-garnet laser", Lasers Med Sci 25:823-828, 2010.

18. Yonca Korkmaz \& Emre Ozel \& Nuray Attar \& Ceren Ozge Bicer \& Erhan Firatli, “ Microleakage and scanning electron microscopy evaluation of all-in-one self-etch adhesives and their respective nanocomposites prepared by erbium:yttrium-aluminum-garnet laser and bur", Lasers Med Sci 25:493-502, 2010.

19. Tahereh Fattah \& Haleh Kazemi \& Reza Fekrazad \&Hadi Assadian \& Katayoun A. M. Kalhori, “ Er,Cr:YSGG laser influence on microleakage of class Vcomposite resin restorations", Lasers Med Sci 28:1257-1262, 2013.

20. Ferracane JL, Berge HX, Condon JR, In vitro aging of dental composites in water-effect of degree of conversion, filler volume, and filler/matrix coupling, J Biomed Mater Res 42:465-472, 1998.

21. Santerre JP, Shajii L, Leung BW, “ Relation of dental composite formulations to their degradation and the release of hydrolyzed polymeric-resin-derived products", Crit Rev Oral Biol Med 12:136-151, 2001.

22. F. L. B. Amaral \& V. Colucci \& A. E. Souza-Gabriel \& M. A. Chinelatti \& R. G. Palma-Dibb \& S. A. M. Corona “ Bond durability in erbium:yttrium-aluminum-garnet laser-irradiated enamel", Lasers Med Sci 25:155-163, 2010.
23. R. Osorio, M. Toledano, E. Osorio, F. S. Aguilera, F. R. Tay, " Effect of load cycling and in vitro degradation on resindentin bonds using a self-etching primer “, DOI: 10.1002/ jbm.a.30274,2004.

24. E. Yassini, H. Kermanshah, M. Mirzaei, B. Ranjbar Omidi, " Effect of mechanical load cycling on class V glassionomer and composite restorations; a microleakage and scanning electron microscopic evaluation “, The Journal of Islamic Dental Association of IRAN, Vol. 24, No. 2, 2012 .

25. Samer Hakimeh,a Jayalakshmi Vaidyanathan,b Milton L. Houpt,a Tritala K, Vaidyanathan, and Stanley Von Hagen, "Microleakage of compomer Class V restorations: Effect of load cycling, thermal cycling, and cavity shape differences”, J Prosthet Dent ;83:194-203, 2000.

26. Gullshang Muhammed \& Raad Dayem, “ Evaluation of the microleakage of different class $\mathrm{V}$ cavities prepared by using Er:YAG laser, ultrasonic device, and conventional rotary instruments with two dentin bonding systems “, Lasers Med Sci, 1519-2, 2014.

27. Ozgul BAYGIN, Fatih Mehmet KORKMAZ and Ipek ARSLAN, "Effects of different types of adhesive systems on the microleakage of compomer restorations in Class $\mathrm{V}$ cavities prepared by Er,Cr:YSGG laser in primary teeth “, Dental Materials Journal ; 31(2): 206-214, 2012. 